\title{
Getting Students Back on Track: Persistent Effects of Flipping Accelerated Organic Chemistry on Student Achievement, Study Strategies, and Perceptions of Instruction
}

\author{
Lynn C. Reimer ${ }^{1}$, Wenliang He ${ }^{2, \dagger}$, Renée D. Link ${ }^{\star, 3}$
}

${ }^{1}$ Education Programs, University of California-Merced, Merced, California, 95343, United States

${ }^{2}$ School of Education, University of California-Irvine, Irvine, California, 92697, United States

${ }^{3}$ Department of Chemistry, University of California-Irvine, Irvine, California, 92697, United States

\section{Abstract}

Converting a first-term, accelerated summer organic chemistry course to a flipped format narrowed the achievement gap between students seeking to get ahead in their course of study and those repeating the course. Exam performance improved in the following course in the sequence (taught in traditional format) for students who had previously failed the first-term course. While most students responded positively to the new course structure, repeating students held a stronger preference for the flipped format. These findings provide guidance on how to create courses that promote equity, access and retention of diverse students in STEM.

\section{Graphical Abstract}
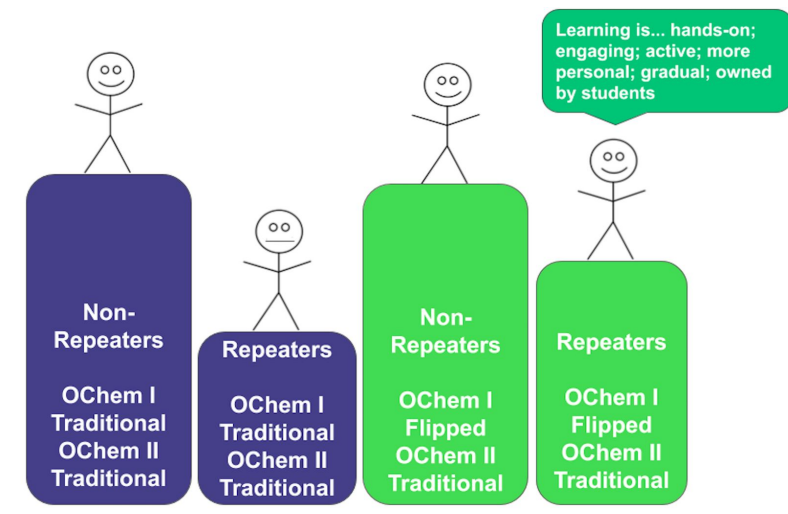

KEYWORDS

Second-year Undergraduate, Organic Chemistry, Constructivism, Student-Centered Learning, Learning Theories, Chemical Education Research 


\section{INTRODUCTION}

While more first-generation, low-income, underrepresented minority (URM) and female undergraduates are entering science, technology, engineering, and math (STEM) majors, a disproportionate number end up graduating in non-STEM disciplines. ${ }^{1-3}$ Only forty percent obtain a STEM degree within six years. ${ }^{2}$ Organic chemistry is considered one of the most challenging introductory science courses, with failure and withdrawal rates often higher than other lower division STEM courses..$^{4,5}$ Traditional lectures continue to dominate at larger universities, in which students passively take notes and complete homework after class, with minimal opportunity for immediate feedback, peer interaction, or collaborative problem solving. ${ }^{6}$ In response, partial or complete flipped instruction has increased to address these concerns. ${ }^{7}$ Initial successes in Biology, General Chemistry and Physics at this study's institution inspired the redesign of an accelerated summer Organic Chemistry course. ${ }^{8,9}$

\section{Flipped Instruction}

In general, flipped instruction refers to any course where content delivery is completed before class through videos and textbooks, freeing up class time for student-centered, active learning. ${ }^{7}$ Learning activities may include: working problems on paper, using model kits to investigate three-dimensional structures, and acting out chemical processes. Frequently larger classes include an electronic response system, such as iClickers $(\mathcal{C}$ or TopHat $\mathcal{C}$, to gauge completion of pre-class work, formatively assess students during learning activities, facilitate peer-peer interaction, and increase engagement. ${ }^{10,11}$ Instructors may also rely on teaching assistants and peer leaders (i.e., learning assistants) to provide instructional support during in-class learning activities. ${ }^{12}$

Numerous studies on flipped instruction in undergraduate STEM courses have shown positive results, including studies on large fully or partially flipped chemistry courses. These studies typically focus on outcomes in the current course, rather than long-term benefits. Less is known about the effects of flipped instruction in large enrollment, organic chemistry courses at large, public research universities when taught in an accelerated summer term. 
Flipped Instruction in Large General Chemistry Courses

Yesterbsky found a small increase in final course grades for a fully flipped general chemistry course (415 students). ${ }^{13}$ Eichler and Peeples found a small positive effect on overall course grade and a decrease in fail/withdrawal rates (452 students). ${ }^{10}$ Bokosmaty and colleagues observed an increase in course grades and decrease in failure rates in partially flipped introductory and general chemistry courses. ${ }^{14}$ In a large general chemistry course, a flipped instruction section (334 students) was compared with a traditional lecture format (343 students) taught by the same instructor during the same term. ${ }^{8}$ Researchers found that flipped instruction was associated with a small positive increase on final exam performance while not increasing student study time. Student perceptions of poor course quality were largely identified to be related to the non-compliance of pre-class assignment completion. In a similar study, only sophomores and females seemed to benefit from the flipped instruction, as measured by both final exam outcomes, and post-course performance even though there were numerous technology challenges. ${ }^{15}$

Comparing flipped and traditional general chemistry courses with total enrollments of 117-206 students, Ryan and Reid found a small increase in final exam scores for students in the lower third of the class, based on pretest scoring. ${ }^{16}$ Recently, Deri and colleagues demonstrated a decrease in fail/withdrawal rates and an increase in course grades compared with historical trends of traditional lecture general chemistry courses enrolling up to 1,000 students per class across two campuses of a large, urban, public university. ${ }^{17}$ Importantly, this work indicated larger gains for students at the campus whose demographics include a larger number of first-generation college students with lower SAT scores and coming from lower-performing high schools.

Flipped Instruction in Large Organic Chemistry Courses

Fewer studies on flipped learning in organic chemistry courses can be found in the literature. In a fully flipped organic chemistry course, Flynn identified a small increase in final exam scores and decrease in fail/withdrawal rates. ${ }^{18}$ Rein and Brookes found no change in exam scores or course completion rates in a partially flipped organic chemistry course, but did find a small positive change to student responses in course evaluations. ${ }^{19}$ Shattuck reported increased performance on exam 
questions, increased grade outcomes, and shift to more favorable views of flipped instruction in a small, partially flipped organic chemistry course. ${ }^{20}$ In a fully flipped first semester organic chemistry course, Mooring identified no impact on final exam scores as compared with a traditional class but did observe an increase in A and B course grades and a decrease in the DFW rate compared with historical data. ${ }^{21}$ A positive effect on students' emotional satisfaction and ratings of the intellectual accessibility of the course were also observed. Crimmins and Midkiff found students in a flipped course, which authors referred to as "highly structured," scored higher on the final exam and earned overall higher course grades compared with the historical traditional course; students in the 25th and 50th percentile experienced the greatest benefit. ${ }^{22}$ As with most studies, no demographic data (e.g., race and first-generation status) were reported, nor discussion of students who may have previously failed the course, only those students identified as academically weaker.

\section{Persistent Effects of Flipped Instruction}

Even fewer studies have reported on whether flipped instruction may be associated with student achievement in subsequent courses. In a study by Hibbard, a small but statistically significant increase in student performance on the cumulative ACS standardized exam was observed after a full year of a semi-self-paced flipped general chemistry course format. ${ }^{23} \mathrm{He}$ and colleagues found that students in a partially flipped general chemistry course showed an overall positive effect on end of course motivation and post-course grades, approximately half a letter grade higher on average. A differentiated impact was seen, whereby academically weaker students showed higher motivation increases, and higher gains in post-course motivation. A "softer" approach to flipping was identified as the main mechanism for the gains seen in this study as compared with previous studies completed by the researchers in fully flipped classrooms. ${ }^{24}$

While studies of flipped courses, including larger enrollment courses, have increased in recent years, studies describing large organic chemistry courses in a flipped format are less common; studies reporting on a diverse student body are minimal. Finally, no studies to date have examined the long-term effect of a flipped organic chemistry course taught at an accelerated pace, with a focus on 
students repeating the course after an unsuccessful attempt. The current study implemented flipped instruction in an organic chemistry course as a means to increase student achievement long term. ${ }^{25}$ This study is unique in that it focused on an accelerated summer course with a diverse student enrollment, including many who had previously failed the course and were thus taking the summer course to "get back on track."

\section{Theoretical Framework}

Two bodies of research on student performance and persistence framed this work: culturally responsive teaching and social/academic integration. It is well known that underrepresented students underperform in undergraduate STEM courses. ${ }^{2}$ One explanation is cultural mismatch--certain groups of students are disadvantaged because of conflicts between implicit expectations for autonomy in American higher education and cultural identity. ${ }^{26-29}$ Because learning is a cultural process, culturally responsive teaching creates a learning environment that accommodates students' interdependent learning norms, tapping into students' prior experiences and knowledge to increase student performance and persistence. ${ }^{30,31}$ Social (and academic) integration also contribute to persistence..$^{32}$ Unfortunately, means of increasing social integration are frequently extra-curricular, co-curricular, or supplemental to classroom instruction. This study sought to increase social and academic integration within the classroom by employing culturally responsive teaching, thereby improving student performance, persistence, and matriculation into STEM careers..$^{29,33}$ For students who have previously failed Organic Chemistry and are trying to "get back on track" during a summer accelerated course, flipped, interactive instruction--culturally responsive teaching that promotes social and academic integration--may help reduce the achievement gap in performance and persistence.

\section{Research Questions}

To determine whether a flipped format in an accelerated summer organic chemistry class is associated with a positive effect on student performance and persistence, we sought to answer the following questions: 
- How do students' midterm and final exam scores in Organic Chemistry II compare between students who took the flipped, accelerated Organic Chemistry I course and students who took the traditional, accelerated Organic Chemistry I course? ${ }^{34}$

- Will a flipped, accelerated Organic Chemistry I format reduce the achievement gap for students who have previously attempted the course during a regular academic term and failed?

- What were students' perceptions of the course structure and their own skill development in the flipped Organic Chemistry I course?

\section{Methods}

Participants and Setting

The current study included five consecutive accelerated summer terms from 2009 to 2013, at a large public research university in the western United States. ${ }^{35}$ This institution is quite diverse. In 2013, students self-reported as $43 \%$ Asian, $22 \%$ Hispanic, $16 \%$ non-resident, $11 \%$ white, $4 \%$ other and $4 \%$ who declined to state. Additionally, $49 \%$ of the students self-reported as first-generation college students, and 35\% were identified as low-income based on Pell grant eligibility. The student population is $50 \%$ male, $50 \%$ female. The university's Institutional Review Board approved the study, including FERPA compliance.

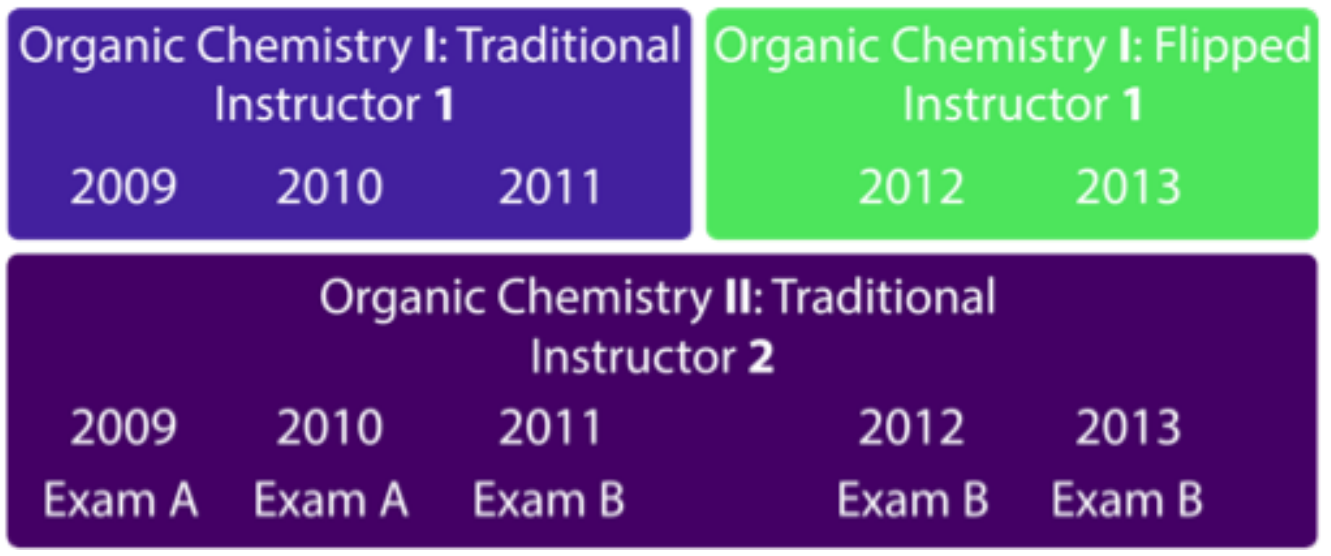

Figure 1. Five-year Course and Final Exam Formats

Each summer, Instructor 1 taught Organic Chemistry I in Summer Session I, while Instructor 2 taught Organic Chemistry II in Summer Session II (Figure 1). In both accelerated courses, students 
met for two-hour sessions three times a week. In Organic Chemistry I, Instructor 1 used traditional face-to-face instruction from 2009 to 2011, and then flipped instruction in 2012 and 2013. Instructor 2 used a traditional lecture format in Organic Chemistry II during all five years. Summer 2011 is used as the baseline, as 2011 was the third consecutive summer that Instructor 1 had taught this course, providing a more stable comparison with Instructor 2, who had taught for 12 years. Although midterm exam questions were not identical between years of Organic Chemistry II, taught consistently by Instructor 2, they were isomorphic in nature, measuring the same set of concepts with cosmetic changes in detail. An identical final exam was administered in Organic Chemistry II in 2009 and 2010. This exam was isomorphic to the final exam administered in Organic Chemistry II during 2011, 2012 and 2013; these three were identical, further supporting 2011 as the comparison group. During years 2011 - 2013, enrollment in the courses was consistently higher than in 2009 and 2010, and met the standard criteria for "large enrollment". ${ }^{25}$ In all years, students had access to graded midterm exams but not to graded final exams.

\section{Table 1. Accelerated Organic Chemistry I (OC I) and Organic Chemistry II (OC II) Enrollment}

\begin{tabular}{|c|c|c|c|c|c|c|c|c|c|c|c|c|}
\hline & \multicolumn{2}{|c|}{2009} & \multicolumn{2}{|c|}{2010} & \multicolumn{2}{|c|}{$\begin{array}{c}\text { Baseline* }^{*} \\
2011\end{array}$} & \multicolumn{2}{|c|}{2012} & \multicolumn{2}{|c|}{2013} & \multicolumn{2}{|c|}{ Total } \\
\hline & OC I & OC II & OC I & OC II & OC I & OC II & OC I & OC II & OC I & OC II & OC I & OC II \\
\hline Total & 167 & 136 & 135 & 139 & 218 & 165 & 259 & 172 & 200 & 238 & 979 & 850 \\
\hline Common & \multicolumn{2}{|c|}{96} & \multicolumn{2}{|c|}{58} & \multicolumn{2}{|c|}{51} & \multicolumn{2}{|c|}{94} & \multicolumn{2}{|c|}{75} & \multicolumn{2}{|c|}{$374^{* *}$} \\
\hline
\end{tabular}

All students included in the study were regularly matriculated at the university. Virtually all students made enrollment decisions prior to the first summer session, making it highly unlikely for students to make enrollment decisions for session two based on their learning experience in session one. Because the courses were offered in accelerated summer terms, two distinct student populations 
were present: a) advantaged "Non-Repeaters," those seeking to accelerate their progress towards degree completion, having not completed any prior organic chemistry courses; and b) at-risk "Repeaters," those students who had previously failed Organic Chemistry I one or more times. During the five year study, 979 students enrolled in Organic Chemistry I and 850 students enrolled in Organic Chemistry II; 374 students took both courses consecutively, of whom 40\% (148 students) were Repeaters taking Organic Chemistry I after an unsuccessful attempt in the previous academic year. An additional 11 students enrolled in Organic Chemistry I after multiple failed attempts in the prior academic year. Because no statistical differences were found between the two groups of students repeating Organic Chemistry I, both groups are included together and referred to as "Repeaters" in our analysis (159 students; 43\%).

Flipped Course Description

Before class, students were assigned material to review in a manner of their choosing: either read textbook sections, watch short lecture videos (podcasts), or both. Copies of slides with blanks facilitated note-taking of the material. The online homework system provided pre-class quizzes (3-5 multiple choice content questions and one open-ended question regarding what the student found most difficult). This accountability mechanism was designed only to verify that students had completed the assigned reading or video segments rather than to probe specific knowledge and afforded students the opportunity to work collaboratively.

During class, students worked on problems designed to guide their progression through the concepts presented in the pre-class materials. In-class activities included working problems on paper, using model kits to investigate three-dimensional structures, and acting out chemical processes. For example, during a class period focusing on conformational analysis, pairs of students built models representing two similarly substituted cyclohexane structural drawings and worked together to determine whether their models represented conformers or stereoisomers. When working on nucleophilicity trends, a group of students volunteered to act out roles as solvent molecules and nucleophiles of varying sizes, with the solvent molecule students attempting to "trap" the nucleophile 
students. For all in-class activities, students were strongly encouraged to work with peers but could work alone if they preferred. Most students chose to work with classmates despite the difficulties for facilitating group work presented by the fixed seating format of the classroom. Student work for in-class activities was not collected and did not count for any credit toward final grades.

After class, students completed homework through an online homework system for additional practice. To keep the Organic Chemistry I workload hours comparable between the traditional (2009-2011) and flipped courses (2012 \& 2013), these homework assignments for the flipped course were pared down versions of the homework assignments used in the traditional lecture format. Any questions removed in the lighter homework assignments were moved to optional assignments that students could complete for practice but not for credit. In both formats the course structure included a 1-hour discussion section each week in which the graduate student teaching assistant provided additional practice worksheets; students chose to work independently or as a group.

Measurements

Student outcomes were based on exam performance in Organic Chemistry II, as a measure of persistence. Student scores from the two midterms and the final exam for Organic Chemistry II were collected and standardized. Student exam performance in Organic Chemistry II in 2012 and 2013 was compared with 2011, the last traditional lecture year for Organic Chemistry I (Figure 1). Students in the flipped Organic Chemistry I course were surveyed in 2012 and 2013 to gauge their perceptions of the flipped class. Survey topics included pre-class activities (textbook, podcasts, note taking), class activities, discussion section attendance, message board usage, and homework completion. In 2012, only a post-survey was administered; most questions were 5 -item likert scales, a few provided answer choices, and a few were open ended. In 2013, a 6-point likert scale eliminated the neutral option. In 2013, a pre-survey was also administered with additional questions to identify any pre-post changes.

\section{RESULTS}

Multiple regression analysis was conducted using standardized $z$-scores for each exam as the dependent variables. ${ }^{36}$ Scores from 2011 were used as the baseline for subgroup comparisons. Table 2 below provides evidence of the significant achievement gap between students who had failed Organic 
Chemistry I previously and those who had not. The average on the final exam for advantaged Non-Repeaters in the baseline year was 57 out of 100 points; they scored 0.508 standard deviations $(p$ $<.001)$ above the overall class average $(47 / 100)$ on the final exam in Organic Chemistry II. This advantage remained consistent throughout the study (see Table 3). However, students who repeated and passed Organic Chemistry I during the first summer term performed consistently lower on the midterms and final exam in Organic Chemistry II in the second summer term compared with advantaged Non-Repeaters, specifically 1.243 standard deviations lower on the final exam $(p<.001)$, a gap of 16 points. In 2011, the average exam score for Repeaters was 31 points. A similar performance gap was found on the first midterm, 0.311 standard deviations higher $(p<.01)$ than class average, compared with 1.098 standard deviations lower $(p<.001)$, as well as the second midterm exam, 0.307 standard deviations higher $(\mathrm{p}<.05)$ than class average, compared with 0.96 standard deviations lower $(p<.001)$

Table 2. Non-Repeaters Advantage in OC II Scores taking OC I and OC II Consecutively

\begin{tabular}{lccccccccc} 
& \multicolumn{3}{c}{ Midterm 1 } & \multicolumn{3}{c}{ Midterm 2 } & \multicolumn{3}{c}{ Final Exam } \\
& Estimate & $\mathrm{SE}$ & $\mathrm{p}$-value & Estimate & $\mathrm{SE}$ & $\mathrm{p}$-value & Estimate & $\mathrm{SE}$ & $\mathrm{p}$-value \\
NR SS11 & 0.311 & 0.118 & $0.009^{* *}$ & 0.307 & 0.121 & $0.011^{*}$ & 0.508 & 0.116 & $0.000^{* * *}$
\end{tabular}

Performance Gap Between Advantaged and Repeating Students

\begin{tabular}{|c|c|c|c|c|c|c|c|c|c|}
\hline & \multicolumn{3}{|c|}{ Midterm 1} & \multicolumn{3}{|c|}{ Midterm 2} & \multicolumn{3}{|c|}{ Final Exam } \\
\hline & Estimate & SE & p-value & Estimate & $\mathrm{SE}$ & $\mathrm{p}$-value & Estimate & $\mathrm{SE}$ & p-value \\
\hline Repeaters & -1.098 & 0.196 & $0.000 * * *$ & -0.96 & 0.202 & $0.000^{* * *}$ & -1.243 & 0.195 & $0.000 * * *$ \\
\hline
\end{tabular}

Converting Organic Chemistry I to the flipped format significantly narrowed the performance gap

(Figure 2). Repeaters show a statistically significant improvement in Organic Chemistry II, averaging

0.641 standard deviations higher across all exams as compared with the at-risk Repeaters in 2011

(Table 3). Specifically, Repeaters scored $0.595(p<.001 ; 2012 ; 38 / 100)$ and $0.615(p<.001 ; 2013$;

38/100) standard deviations higher on the Organic II final exam, having taken the flipped version of Organic Chemistry I, as compared with their 2011 cohort counterparts $(31 / 100)$. The effect of the flipped instruction in Organic Chemistry I was strongest on the first midterm, $0.792(p<.01 ; 2012)$ 
and $0.745(p<.05 ; 2013)$ standard deviations higher, but remains statistically significant through the final exam. Advantaged Non-Repeaters experienced no benefit or harm from the change in Organic Chemistry I format (Table 4).

\section{Average Exam Scores by Group}
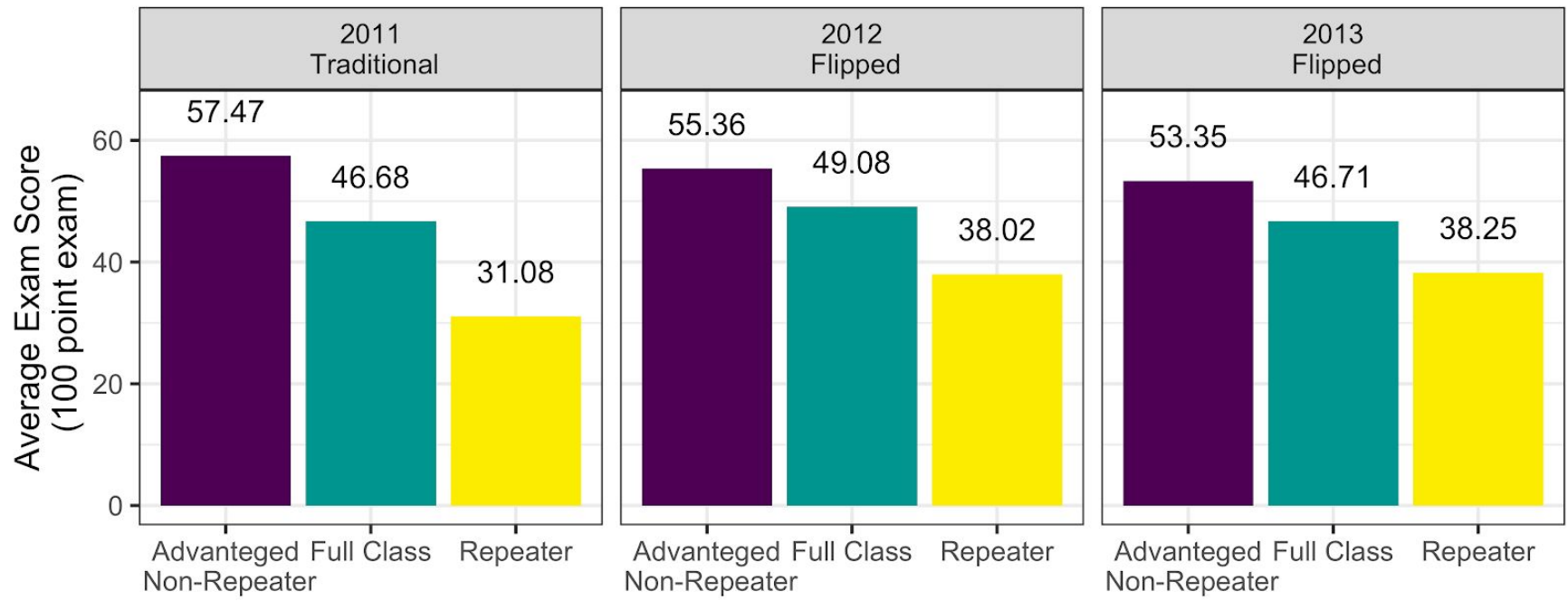

Figure 2. Comparison of Calculated Average Score on Final Exams from Model Predictions for Groups versus Actual Class Average. Changes in Repeater Group Were Statistically Significant While Changes in Non-Repeater Group Were Not Significant.

Table 3. OC II Scores for Repeating Students taking OC I and OC II Consecutively Compared with OCII 2011 Repeaters

\begin{tabular}{|c|c|c|c|c|c|c|c|c|c|}
\hline & \multicolumn{3}{|c|}{ Midterm 1} & \multicolumn{3}{|c|}{ Midterm 2} & \multicolumn{3}{|c|}{ Final Exam } \\
\hline & Estimate & $\mathrm{SE}$ & $\mathrm{p}$-value & Estimate & $\mathrm{SE}$ & $\mathrm{p}$-value & Estimate & $\mathrm{SE}$ & $\mathrm{p}$-value \\
\hline $\begin{array}{l}2009 \\
\text { Repeaters }\end{array}$ & 0.199 & 0.318 & 0.531 & 0.027 & 0.326 & 0.934 & 0.476 & 0.312 & 0.128 \\
\hline $\begin{array}{l}2010 \\
\text { Repeaters }\end{array}$ & 0.8 & 0.38 & $0.036^{*}$ & 0.205 & 0.389 & 0.598 & 0.309 & 0.381 & 0.419 \\
\hline $\begin{array}{l}2012 \\
\text { Repeaters }\end{array}$ & 0.792 & 0.274 & $0.004^{* *}$ & 0.713 & 0.281 & $0.011^{*}$ & 0.595 & 0.269 & $0.028 *$ \\
\hline $\begin{array}{l}2013 \\
\text { Repeaters }\end{array}$ & 0.745 & 0.29 & $0.011^{*}$ & 0.387 & 0.298 & 0.195 & 0.615 & 0.288 & 0.034 * \\
\hline
\end{tabular}

Table 4. OC II Scores for Non-Repeaters taking OC I and OC II Consecutively Compared with OCII 2011 Non-Repeaters taking OC I and OC II Consecutively

Estimate $\quad$ SE $\quad$ p-value Estimate $\quad$ SE $\quad$ p-value Estimate $\quad$ SE $\quad$-value




\begin{tabular}{|c|c|c|c|c|c|c|c|c|c|}
\hline $\begin{array}{l}2009 \\
\text { Non-Repeaters }\end{array}$ & 0.078 & 0.194 & 0.687 & 0.203 & 0.200 & 0.311 & -0.084 & 0.192 & 0.661 \\
\hline $\begin{array}{l}2010 \\
\text { Non-Repeaters }\end{array}$ & -0.104 & 0.187 & 0.577 & -0.062 & 0.190 & 0.743 & -0.201 & 0.181 & 0.266 \\
\hline $\begin{array}{l}2012 \\
\text { Non-Repeaters }\end{array}$ & -0.149 & 0.184 & 0.419 & -0.234 & 0.188 & 0.213 & -0.181 & 0.180 & 0.315 \\
\hline $\begin{array}{l}2013 \\
\text { Non-Repeaters }\end{array}$ & -0.37 & 0.198 & 0.062 & -0.235 & 0.202 & 0.244 & -0.353 & 0.195 & 0.072 \\
\hline
\end{tabular}

Results from the surveys include both Likert scale items and open-ended questions. ${ }^{37-41}$ The majority of students felt the in-class activities were beneficial, that the flipped format (listening to lectures outside of class and working on problem-solving in class) was effective, and would prefer to take more flipped courses. Likert rankings were either "disagree-agree" or "ineffective-effective," as appropriate to the survey statements and employed a 5-point scale. The findings are even more compelling when Non-Repeaters and Repeaters are separated (Figures 3-4). 


\section{Non-Repeating Students' Survey Responses}

I think that having class podcasts available benefited me as a student.

I think that the Sapling homework benefited me as a student.

I feel that the problems on Sapling correlated with what material I learned in each chapter. I always watched the assigned podcasts before class.

I think that discussion sections benefited me as a student.

When I watched the class podcasts I took notes.

I think that in-class activities benefited me as

I think listening to lecture outside of class and working on problem solving in class is an effective way to learn. I would recommend a inverted class to my friends who need to take organic chemistry.

I fully participated in class activities.

I would prefer to take more science classes that use this type of class format.

On average, I read the appropriate textbook section (never-always)

I prefer this classroom format to a traditional lecture format.

I enjoyed working with other students during class.

There is too much work outside of class time in this course as compared to other science courses.

When I watched the class podcasts I wrote down questions

When I watched the class podcasts I also did other thing not related to class.

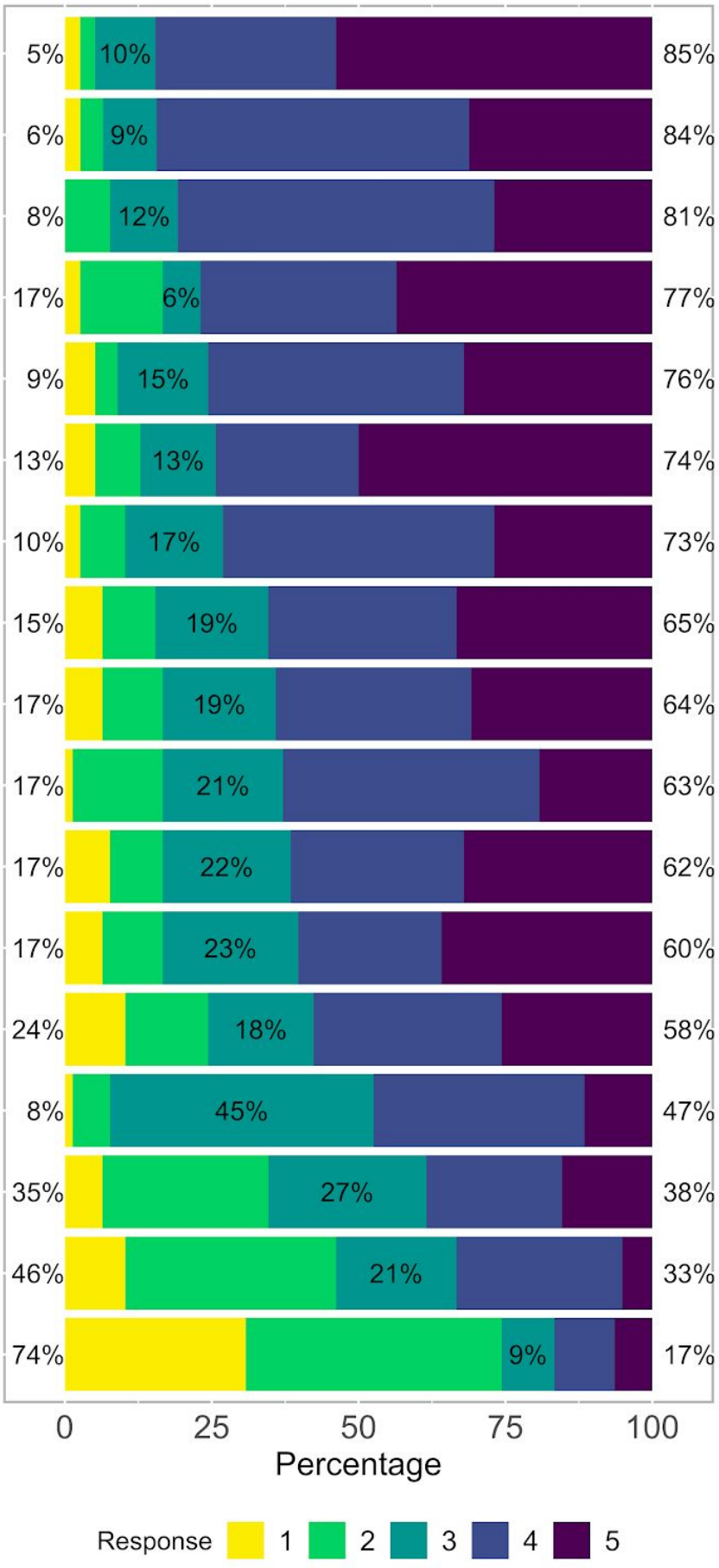

Figure 3. Ranked Percentage Plots of Likert Items for Non-Repeating Students (2012). Values indicate percentages of disagree, neutral, and agree responses. 


\section{Repeating Students'}

Survey Responses

I think listening to lecture outside of class and working on problem solving in class is an effective way to learn.

I think that having class podcasts available benefited me as a student.

I think that in-class activities benefited me as a student.

I feel that the problems on Sapling correlated with what material I learned in each chapter.

I would recommend a inverted class to my friends who need to take organic chemistry.

I think that the Sapling homework benefited me as a student.

I would prefer to take more science classes that use this type of class format.

I fully participated in class activities.

I always watched the assigned podcasts before class.

When I watched the class podcasts I took notes.

I think that discussion sections benefited me as a student.

I prefer this classroom format to a traditional lecture format.

On average, I read the appropriate textbook section (never-always)

I enjoyed working with other students during class.

When I watched the class podcasts I wrote down questions.

There is too much work outside of class time in this course as compared to other science courses.

When I watched the class podcasts I also did other thing not related to class.

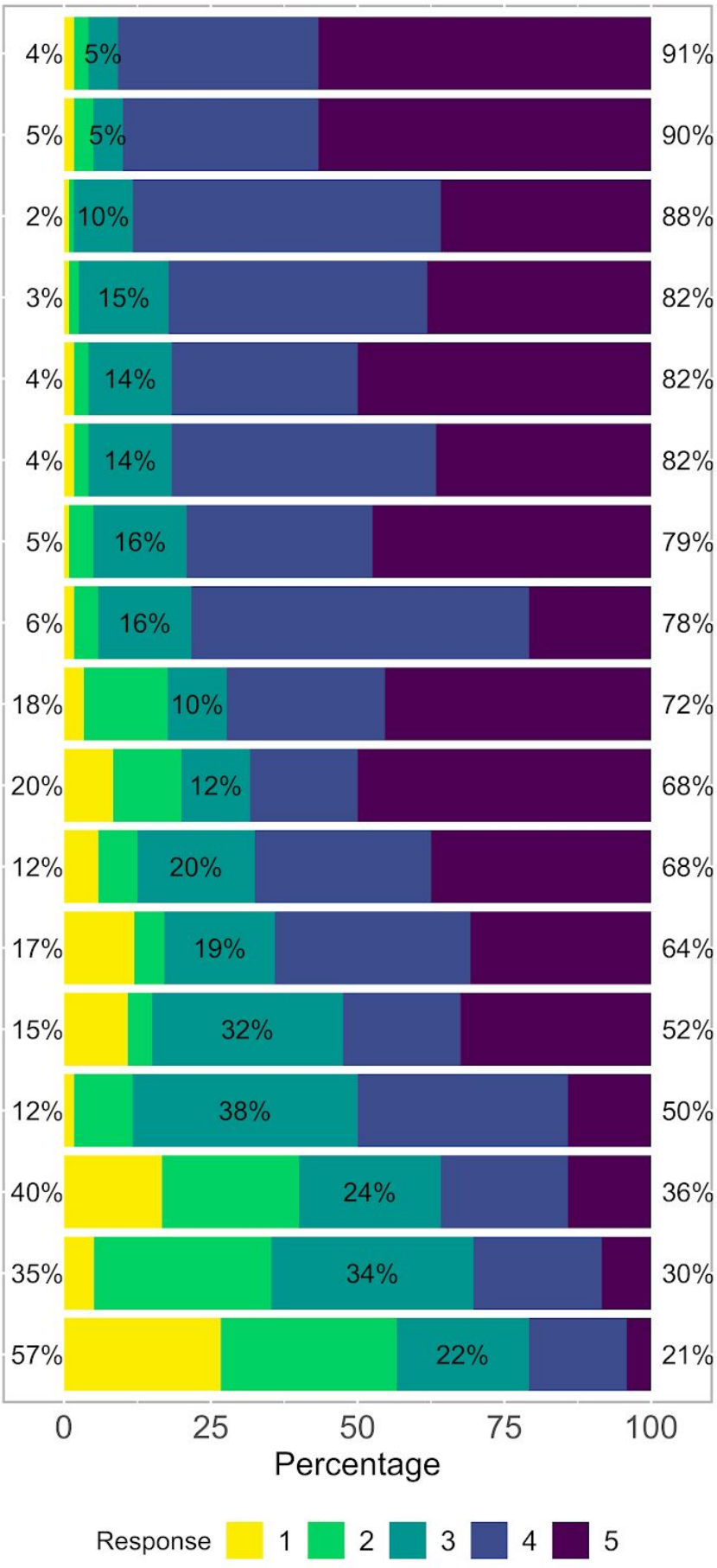

Figure 4. Ranked Percentage Plots of Likert Items for Repeating Students (2012). Values indicate percentages of disagree, neutral, and agree responses. 
We used Wilcoxon rank sum tests with continuity corrections (two-tailed) to identify any items that were statistically significantly different between Non-Repeaters and Repeaters (Table 5). Repeaters' preferences for the flipped format were statistically higher than advantaged Non-Repeaters. This may allude to Repeaters' sense of social and academic integration resulting from culturally responsive teaching.

\section{Table 5. Comparison of Non-Repeaters and Repeaters on 2012 Survey Items}

\begin{tabular}{llll} 
Survey Question & $\begin{array}{l}\text { Non-Repeaters } \\
\text { mean (sd) }\end{array}$ & $\begin{array}{l}\text { Repeaters } \\
\text { mean (sd) }\end{array}$ & p-value \\
$\begin{array}{l}\text { I think that in-class activities benefited me as a } \\
\text { student. }\end{array}$ & $3.87(0.99)$ & $4.22(0.72)$ & $0.017^{*}$ \\
$\begin{array}{l}\text { I would recommend an inverted class to my friends } \\
\text { who need to take organic chemistry. }\end{array}$ & $3.72(1.19)$ & $4.26(0.91)$ & $0.001^{* *}$ \\
$\begin{array}{l}\text { I think listening to lecture outside of class and } \\
\text { working on problem solving in class is an effective } \\
\text { way to learn. }\end{array}$ & $3.77(1.19)$ & $4.42(0.84)$ & $0.000^{* * *}$ \\
$\begin{array}{l}\text { I would prefer to take more science classes that use } \\
\text { this type of class format. }\end{array}$ & $3.69(1.23)$ & $4.21(0.91)$ & $0.004^{* *}$ \\
$\begin{array}{l}* * * \\
*\end{array}<.001 .{ }^{* *} p<.01 .{ }^{*} p<.05$. & & & \\
\hline
\end{tabular}

For 2013, we used a 6-point scale and administered a pre- and post-survey. The 2013 surveys had different questions. We hoped to obtain more detailed information and see if there were any significant changes from the beginning of the class to the end of the class. Similar to results for 2012, we found the majority of students in 2013 preferred the flipped format. Repeaters' preference for flipped instructional practices were higher than Non-Repeaters, but not statistically different (Figures 5 and $6)$. 


\section{Non-Repeating Students' Survey Responses}

Beyond this summer session, this course will still be very useful to me.

Having class podcasts available

I am highly motivated to do well in this course.

Learning before class

Doing Sapling homework

I am very interested in the content area of this

course.

This course as a whole

Learning before class helped me find out things I didn't understand.

I frequently took notes when learning new material before class.

The in-class activities often answered questions

I had from learning before class.

Participating in various in-class activities I frequently summarized important points in notes when learning before class.

I prefer this learn-before-class format to a "traditional lecture" format.

Attending discussion sections

I was intellectually engaged in class throughout

I would like to take more science classes using

this type of class format.

I am very confident that I will do well in this course.

Knowing exactly what I didn't understand made me more likely to ask questions.

Working with other students during class

I asked other students for help.

I preferred not to ask others for help, even when

I couldn't figure things out.

I frequently wrote down questions I had when learning new material before class.

I asked the instructor or the TA for help after class.

I asked questions directly during class.

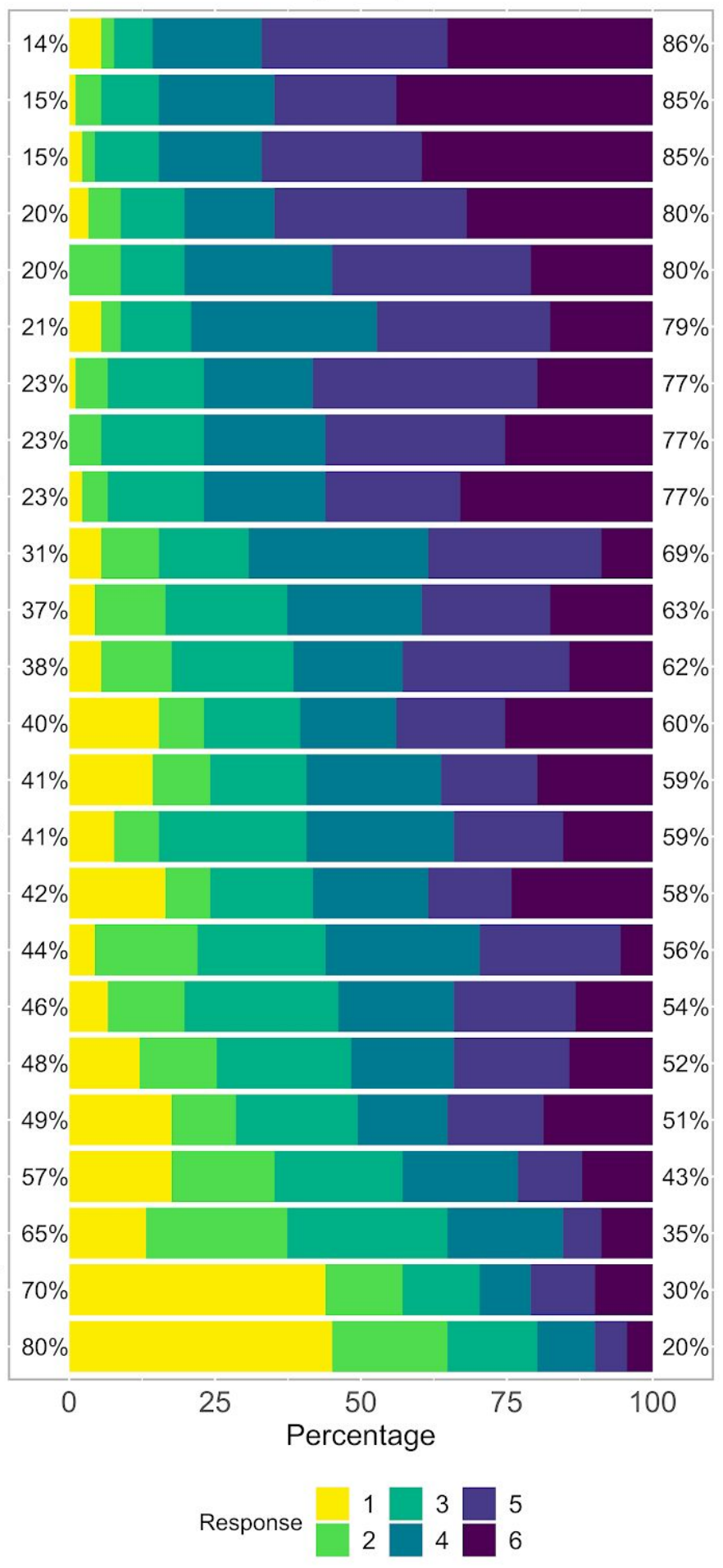


Figure 5. Ranked Percentage Plots of Likert Items for Non-Repeating Students (2013). Values indicate percentages of disagree and agree responses.

\section{Repeating Students' Survey Responses}

Having class podcasts available Learning before class

I am highly motivated to do well in this course.

Doing Sapling homework

This course as a whole

Beyond this summer session, this course will still be very useful to me.

I frequently took notes when learning new material before class. Learning before class helped me find out things $i$ didn't understand.

I am very interested in the content area of this

I prefer this learn-before-class format to a "traditional lecture" format. I would like to take more science classes using this type of class format. The in-class activities often answered questions I had from learning before class.

Participating in various in-class activities I am very confident that I will do well in this I frequently summarized important points in notes when learning before class.

Attending discussion sections

I was intellectually engaged in class throughout Knowing exactly what I didn't understand made me more likely to ask questions.

I asked other students for help.

I preferred not to ask others for help, even when I couldn't figure things out.

Working with other students during class I frequently wrote down questions I had when learning new material before class. I asked the instructor or the TA for help after class.

I asked questions directly during class.

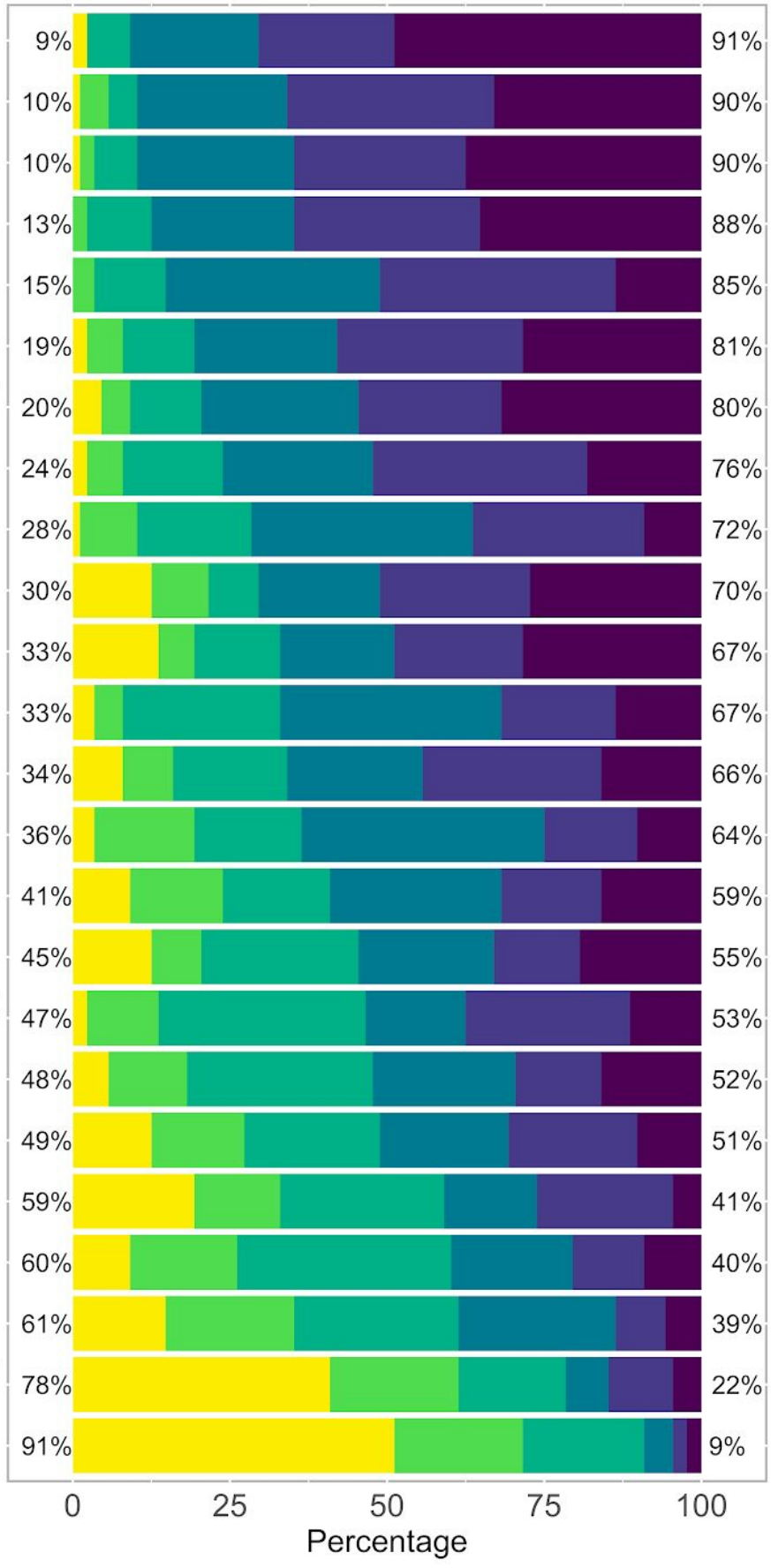

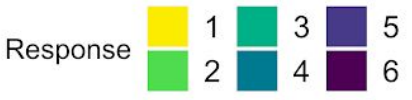


Figure 6. Ranked Percentage Plots of Likert Items for Non-Repeating Students (2013). Values indicate percentages of disagree and agree responses.

Wilcoxon rank sum tests with continuity corrections were run (two-tailed) to identify any items that were statistically significantly different between the 2013 pre- and post-survey. These items focused on study habits, motivation and predicted course grade. While eight items were found to be statistically significant, this may be due to a change in the wording of the question between pre- and post-survey, confounding these results. For example, the pre-survey question asked, "In a regular 10-week quarter, before learning anything from lectures, how many hours per week on average do you spend studying for a typical science or math course in advance?" The average was about four hours, compared with eight hours on the post-survey, which students likely answered according to the accelerated summer flipped course which is only five weeks long. Anecdotally, this means that students studied similarly for the flipped class as any other math or science class. However, there is a noticeable difference in the amount of studying after class, much less for the flipped format (17 hours compared with about 6.5 hours, if we apply the same 10 week to 5 week term formula). The last two survey items show that students' confidence and motivation decrease by the end of the term, which is consistent with the literature. ${ }^{42}$ Of note, by the end of the term, students reported asking more questions directly of the instructor in the flipped, rather than waiting until later to ask the TA or other students. This would support the instructor's culturally responsive teaching and academic integration of the students. In 2013, there were no statistically significant differences between Non-Repeaters and Repeaters.

\section{Table 6. Change Between Pre- Post-survey Items in 2013}

$\begin{array}{llll}\text { Post-survey Question } & \begin{array}{l}\text { Pre-Survey } \\ \text { mean (sd) }\end{array} & \begin{array}{l}\text { Post-Survey } \\ \text { mean (sd) }\end{array} & \text { p-value } \\ \begin{array}{l}\text { On average, I spent } \\ \text { learning course material and doing assigned tasks } \\ \text { before class. }\end{array} & 3.99(4.78) & 8.15(7.25) & 0.000^{* * *} \\ \begin{array}{l}\text { By contrast, I spent about } \\ \text { learning course material and doing assigned tasks }\end{array} & 8.57(7.73) & 6.35(9.64) & 0.000^{* * *}\end{array}$


after class.

I asked questions directly during class.

$1.86(0.91)$

$2.82(1.22)$

$3.86(1.25)$

$2.65(1.33)$

I preferred not to ask others for help, even when I couldn't figure things out.

I am very confident that I will do well in this course.

I am highly motivated to do well in this course.

$4.03(1.09)$

$5.34(0.92)$
$2.09(1.35)$

$0.012^{*}$

$2.49(1.67)$

$0.047^{*}$

$3.55(1.63)$

$0.053+$

$3.22(1.56)$

$0.000^{* * *}$

$3.70(1.28)$

$0.001^{* *}$

$4.86(1.19)$

$0.000^{* * *}$

${ }^{* * *} p<.001 .{ }^{* *} p<.01{ }^{*} p<.05 .+p<.10$.

Finally, students' own wording was used to identify themes in the four open-ended survey questions based on identified relations, similarities and differences that were grouped conceptually. ${ }^{43}$ Common themes described the learning experience as: demanding, engaging, lots of problem solving (with peers), interactive, helpful demonstrations, hands-on (molecule kits) and gaining a deeper understanding. Common caveats included: more work (for students and instructors), more responsibility, and no room to procrastinate. Table 7 provides an overview by question and includes a few representative student quotes.

Table 7. Flipped Organic Chemistry I Student Post-survey Common Responses (2012 and 2013)

\begin{tabular}{|c|c|c|c|}
\hline $\begin{array}{l}\text { What did you think of the } \\
\text { "inverted" method of } \\
\text { teaching the course? }\end{array}$ & $\begin{array}{l}\text { What in-class methods } \\
\text { did you find especially } \\
\text { helpful? }\end{array}$ & $\begin{array}{l}\text { What out-of-class } \\
\text { methods did you find } \\
\text { especially helpful? }\end{array}$ & $\begin{array}{l}\text { How did your study } \\
\text { habits change in the } \\
\text { "inverted" class? }\end{array}$ \\
\hline $\begin{array}{l}\text { Demanding; } \\
\text { More work; } \\
\text { More preparation; } \\
\text { Deeper understanding; } \\
\text { Engaging; } \\
\text { Interactive; }\end{array}$ & $\begin{array}{l}\text { Solving problems; } \\
\text { Challenge problems; } \\
\text { Building with model kits; } \\
\text { iClickers; } \\
\text { Demonstrations; } \\
\text { Peer discussions }\end{array}$ & $\begin{array}{l}\text { Podcasts; } \\
\text { Quizzes before class; } \\
\text { Self-study strategies; } \\
\text { Online homework; } \\
\text { Discussion section }\end{array}$ & $\begin{array}{l}\text { Study more; } \\
\text { Study daily; } \\
\text { No cramming; } \\
\text { No room to procrastinate; } \\
\text { More ownership }\end{array}$ \\
\hline $\begin{array}{l}\text { I failed my first OChem } \\
\text { course...this method has } \\
\text { helped me learn and } \\
\text { succeed...allowed me to } \\
\text { fully understand the } \\
\text { fundamentals...who } \\
\text { would have thought I } \\
\text { would have a strong } \\
\text { interest in organic } \\
\text { chemistry }\end{array}$ & $\begin{array}{l}\text { Working on problems in } \\
\text { which you are given time } \\
\text { to work with peers and } \\
\text { listen to their thoughts } \\
\text { and opinions on the } \\
\text { subject, seeing how they } \\
\text { personally work on } \\
\text { problems...may see } \\
\text { another approach towards } \\
\text { a problem. }\end{array}$ & $\begin{array}{l}\text { Encouraging the podcasts } \\
\text { and readings BEFORE } \\
\text { class...Requiring Sapling } \\
\text { homework after each } \\
\text { podcast...forced students } \\
\text { not to procrastinate... } \\
\text { actually helped learn the } \\
\text { material instead of cram } \\
\text { before exams. }\end{array}$ & $\begin{array}{l}\text { I am more active in } \\
\text { studying and less hesitant } \\
\text { to attempt } \\
\text { problems... because I've } \\
\text { learned the common } \\
\text { mistakes in class and } \\
\text { have my professor...for } \\
\text { questions or struggles I } \\
\text { may be facing. }\end{array}$ \\
\hline
\end{tabular}


It was a little harder since

we, as the students, definitely had a lot more responsibility since we had to take the time to review the subjects we would be talking about in lecture...hard to follow along when I skipped a podcast or two because of lack of time management on my part...

I thought it was useful and more efficient since we were able to do hands on problems during lecture. However for the students that didn't watch the podcasts, lecture was pretty much useless since they didn't know what is going on. It makes you better prepared and avoids procrastination.
I thought working on problems during class slowly was helpful in the chapters that were particularly difficult... Using the 3D model kit was VERY helpful for me and I appreciated how the TA and [Instructor] would walk around to check if students had the right structure.

I especially liked doing practice problems with the class as a whole...awesome when [Instructor] and TA were going around the huge lecture hall answering questions...made me feel like it was a small, interactive class...liked that we could actually keep up with the pace and learn every step.
I felt the podcasts were the most helpful...gave me the ability to listen to the lecture at my own speed...pause...when I didn't fully understand... allowed me to be more productive in class by actually applying the concepts...

Podcasts, since I could review them if needed, and the online pre-class quizzes, so I could see how well I really understood the material and decide what I need to focus my attention on when studying.
With this method, there is no room nor any reason to procrastinate so I just did it, I just studied easily and smoothly...never felt rushed to move onto the next topic...knew there would be time to ask questions and practice with my peers and instructor...I have a strong foundation in O-chem...feels awesome...

It made me realize how much better it is to be prepared... online quizzes...forced me to watch the podcasts and learn the material before class...I always knew what was going on and was never confused... study habits have slowly involved much less procrastinating... grew to appreciate a bit of studying each day

\section{Discussion}

While an achievement gap continues at the end of Organic Chemistry II between advantaged Non-Repeaters and at-risk Repeaters of Organic Chemistry I, the gap was significantly narrowed when Organic Chemistry I was taught in a flipped, interactive format. Because the courses were offered in the accelerated summer term, two distinct student populations were present: a) advantaged "Non-Repeaters," those seeking to accelerate their progress towards degree completion, having not completed any prior organic chemistry courses; and b) at-risk "Repeaters," those students who had previously failed Organic Chemistry I one or more times. One would expect a significant achievement gap between these two groups. Students who fail the first course in the sequence commonly struggle in the remainder of the sequence, even after successfully repeating the initial course. This trend was evident in the analysis of student performance in Organic Chemistry II regardless of the format of the Organic Chemistry I course. However, converting Organic Chemistry I to a flipped format resulted in a 
significant improvement in performance for Repeaters in Organic Chemistry II. While they did not reach the same level as their non-repeating peers, the gap between the two groups was narrowed significantly, potentially increasing their chances of graduating in STEM and pursuing their career goals. Studies that show a gain within the flipped course may be promising, but to show that the gain persists throughout the second course is compelling.

Organic Chemistry has been described as the most difficult STEM gateway course, weeding students out of their STEM major more than any other lower division course, thus contributing to the persistence achievement gap. ${ }^{4,5}$ Increased performance between an intervention and control group within the intervention course would be encouraging but anticipated, otherwise, why change the format? However, higher final exam scores in the next course that significantly narrow the achievement gap in such a pivotal course sequence for STEM majors has implications for increasing graduation rates in STEM and ultimately increasing access to STEM careers for all students.

The flipped format provided many avenues by which students' academic potential could be reached. Cultural mismatch was reduced and social and academic integration were increased. Students found the format to be engaging, active, more personal, and hands-on. They valued the peer discussions, demonstrations, building with model kits, covering the "tricky" practice problems, and iClickers. It should be noted that the iClickers were used as a means to foster peer discussion, rather than as an individual assessment tool. The classroom activities provided opportunities for students to work with one another and learn from one another towards a common goal. Many of the students at this university are first-generation and low-income. Research has shown that these students embody interdependent learning. ${ }^{27}$ The flipped format created a culturally responsive learning environment that enhanced social integration. Through hands-on activities and acting out concepts, students experienced the learning through multiple modalities. This was enhanced by podcasts, reading, note taking, and online homework and quizzes outside of class, all of which students said they found helpful. Rather than assuming the students were enculturated in the norms of higher education, the course explicitly taught and modeled study strategies. It is likely these new skills transferred to the 
next, traditionally taught course. The flipped format not only provided a deeper understanding on the fundamental concepts of Organic Chemistry I, it provided skill development, applicable to future courses, enhancing academic integration. This is especially evident in the students' open-ended, post-survey comments (Table 6).

Another aspect of culturally responsive teaching is reteaching, presenting content with different strategies and approaches that attend to students' needs. ${ }^{44}$ Reteaching material to students (Repeaters) is most successful when it is engaging and interactive (group work), information is in digestible chunks (podcasts), and it includes frequent formative assessment (iClickers) and opportunities for practice. ${ }^{45,46}$ Effective reteaching has not been studied as well at the undergraduate level. Typically students retake previously failed courses, but there is rarely intentional instructional changes to increase success for Repeaters. The findings here affirm that while flipped instruction may be generally preferred and helpful to all students, its significance lies in its commitment to culturally responsive teaching, inclusive of previously unsuccessful students, rather than weeding these students out of STEM courses, majors and careers.

\section{LIMITATIONS}

While this study is potentially generalizable to other public research institutions, there are noteworthy limitations. First, the surveys administered in 2012 and 2013 had different questions. The changes were intended to gather additional details regarding students' study habits; this information is anecdotal and further study is recommended. Second, these surveys had not been validated in a previous study; it would have been best to not change the survey questions in 2013 and thus have a larger sample to run validity tests. Third, the institution's selectivity may have blunted the statistical significance of findings. Students must have scored above 600 on the mathematics portion of the SAT or completed a rigorous set of preparation courses to take introductory (general) chemistry. Students must have successfully completed the introductory (general) chemistry series to enroll in Organic 
Chemistry. Finally, a larger study sample would have allowed additional analysis to eliminate unseen biases.

FUTURE RESEARCH

Additional studies of accelerated summer STEM courses employing culturally responsive teaching are needed. Similarly, studies of culturally responsive instructional practices need to be studied in developmental STEM courses (i.e., pre-chem) that enroll a disproportionate number of underrepresented minority students. These developmental courses are often taught using pre-packaged online programs (i.e., ALEKS), providing minimal opportunity for social or academic integration. 
Associated CONTENT

Supporting Information

Survey Instruments (PDF)

Statistical Models (PDF)

Survey Data Analysis (PDF)

Corresponding Author

*E-mail: rlink@uci.edu

Notes

${ }^{\dagger}$ Current affiliation for Wenliang He: Zhejiang Normal University, Jinhua, Zhejiang, China

The authors declare no competing financial interests.

\section{ACKNOWLEDGEMENTS}

The authors thank their respective universities for providing the support to conduct this study, colleagues who graciously read versions of the manuscript, and students in the 2012-2013 Chem 51A Summer Session courses for their participation. In particular, we thank Amanda Holton for providing editorial comments. We also wish to thank Kate McKnelly for creating the abstract figure and Figure 1.

Finally, we thank the RStats community for helpful R packages and trouble-shooting support.

\section{REFERENCES}

(1) Chen, X. STEM Attrition: College Students' Paths Into and Out of STEM Fields; National Center for Education Statistics, Institute of Education Sciences, Ed.; U.S. Department of Education: Washington, D.C., 2013.

(2) Eagan, K.; Hurtado, S.; Figueroa, T.; Hughes, B. Examining STEM Pathways among Students Who Begin College at Four-Year Institutions. National Academy of Sciences 2014.

(3) Tibbetts, Y.; Harackiewicz, J. M.; Priniski, S. J.; Canning, E. A. Broadening Participation in the Life Sciences with Social-Psychological Interventions. CBE Life Sci. Educ. 2016, 15 (3). https://doi.org/10.1187/cbe.16-01-0001.

(4) Grove, N. P.; Hershberger, J. W.; Bretz, S. L. Impact of a Spiral Organic Curriculum on Student Attrition and Learning. Chem. Educ. Res. Pract. 2008, 9 (2), 157-162.

(5) Grove, N. P.; Bretz, S. L. Perry's Scheme of Intellectual and Epistemological Development as a Framework for Describing Student Difficulties in Learning Organic Chemistry. Chem. Educ. Res. Pract. 2010, 11 (3), 207-211.

(6) Smith, M. K.; Vinson, E. L.; Smith, J. A.; Lewin, J. D.; Stetzer, M. R. A Campus-Wide Study of STEM Courses: New Perspectives on Teaching Practices and Perceptions. CBE Life Sci. Educ. 2014, 13 (4), 624-635.

(7) Seery, M. K. Flipped Learning in Higher Education Chemistry: Emerging Trends and Potential Directions. Chem. Educ. Res. Pract. 2015, 16 (4), 758-768. 
(8) He, W.; Holton, A.; Farkas, G.; Warschauer, M. The Effects of Flipped Instruction on out-of-Class Study Time, Exam Performance, and Student Perceptions. Learn Instr 2016, 45, 61-71.

(9) Moravec, M.; Williams, A.; Aguilar-Roca, N.; O’Dowd, D. K. Learn before Lecture: A Strategy That Improves Learning Outcomes in a Large Introductory Biology Class. CBE Life Sci. Educ. 2010, 9 (4), 473-481.

(10) Eichler, J. F.; Peeples, J. Flipped Classroom Modules for Large Enrollment General Chemistry Courses: A Low Barrier Approach to Increase Active Learning and Improve Student Grades. Chem. Educ. Res. Pract. 2016, 17 (1), 197-208.

(11) Reimer, L. C.; Schenke, K.; Nguyen, T.; O’dowd, D. K.; Domina, T.; Warschauer, M. Evaluating Promising Practices in Undergraduate STEM Lecture Courses. RSF: The Russell Sage Foundation Journal of the Social Sciences 2016, 2 (1), 212-233.

(12) Talbot, R. M.; Hartley, L. M.; Marzetta, K.; Wee, B. S. Transforming Undergraduate Science Education With Learning Assistants: Student Satisfaction in Large-Enrollment Courses. J. Coll. Sci. Teach. 2015, 44 (5), 24-30.

(13) Yestrebsky, C. L. Flipping the Classroom in a Large Chemistry Class-Research University Environment. Procedia Soc Behav Sci 2015, 191, 1113-1118.

(14) Bokosmaty, R.; Bridgeman, A.; Muir, M. Using a Partially Flipped Learning Model To Teach First Year Undergraduate Chemistry. J. Chem. Educ. 2019, 96 (4), 629-639.

(15) He, W., Holton, A.J., Farkas, G. Differentiated Impact of Flipped Instruction: When Would Flipped Instruction Work or Falter? Learn. Teach. 2019, 1 (31).

(16) Ryan, M. D.; Reid, S. A. Impact of the Flipped Classroom on Student Performance and Retention: A Parallel Controlled Study in General Chemistry. J. Chem. Educ. 2016, 93 (1), 13-23.

(17) Deri, M. A.; Mills, P.; Mc Gregor, D. Structure and Evaluation of a Flipped General Chemistry Course as a Model for Small and Large Gateway Science. J Coll Sci Teach 2018, 47, 68-77.

(18) Flynn, A. B. Structure and Evaluation of Flipped Chemistry Courses: Organic \& Spectroscopy, Large and Small, First to Third Year, English and French. Chem. Educ. Res. Pract. 2015, 16 (2), $198-211$.

(19) Rein, K. S.; Brookes, D. T. Student Response to a Partial Inversion of an Organic Chemistry Course for Non-Chemistry Majors. J. Chem. Educ. 2015, 92 (5), 797-802.

(20) Shattuck, J. C. A Parallel Controlled Study of the Effectiveness of a Partially Flipped Organic Chemistry Course on Student Performance, Perceptions, and Course Completion. J. Chem. Educ. 2016, 93 (12), 1984-1992.

(21) Mooring, S. R.; Mitchell, C. E.; Burrows, N. L. Evaluation of a Flipped, Large-Enrollment Organic Chemistry Course on Student Attitude and Achievement. J. Chem. Educ. 2016, 93 (12), 1972-1983.

(22) Crimmins, M. T.; Midkiff, B. High Structure Active Learning Pedagogy for the Teaching of Organic Chemistry: Assessing the Impact on Academic Outcomes. J. Chem. Educ. 2017, 94 (4), 429-438.

(23) Hibbard, L.; Sung, S.; Wells, B. Examining the Effectiveness of a Semi-Self-Paced Flipped Learning Format in a College General Chemistry Sequence. J. Chem. Educ. 2016, 93 (1), 24-30.

(24) He, W.; Holton, A. J.; Farkas, G. Impact of Partially Flipped Instruction on Immediate and Subsequent Course Performance in a Large Undergraduate Chemistry Course. Comput. Educ. 2018, 125, 120-131.

(25) Freeman, S.; Eddy, S. L.; McDonough, M.; Smith, M. K.; Okoroafor, N.; Jordt, H.; Wenderoth, M. P. Active Learning Increases Student Performance in Science, Engineering, and Mathematics. Proc. Natl. Acad. Sci. U. S. A. 2014, 111 (23), 8410-8415.

(26) Inzlicht, M.; Schmader, T. Stereotype Threat: Theory, Process, and Application, 1 edition.; Oxford University Press, 2011.

(27) Stephens, N. M.; Fryberg, S. A.; Markus, H. R.; Johnson, C. S.; Covarrubias, R. Unseen Disadvantage: How American Universities' Focus on Independence Undermines the Academic Performance of First-Generation College Students. J. Pers. Soc. Psychol. 2012, 102 (6), 1178.

(28) Steele, C. M. Whistling Vivaldi: How Stereotypes Affect Us and What We Can Do (Issues of Our Time), Reprint edition.; W. W. Norton \& Company, 2011.

(29) Tinto, V. Completing College: Rethinking Institutional Action; University of Chicago Press, 2012. 
(30) Gay, G. Culturally Responsive Teaching: Theory, Research, and Practice (Multicultural Education Series), 2 edition.; Banks, J. A., Ed.; Teachers College Press, 2010.

(31) Martell, C. C. Race and Histories: Examining Culturally Relevant Teaching in the U.S. History Classroom. Theory \& Research in Social Education 2013, 41 (1), 65-88.

(32) Tinto, V. Dropout from Higher Education: A Theoretical Synthesis of Recent Research. Rev. Educ. Res. 1975, 45 (1), 89-125.

(33) Engle, J.; Tinto, V. Moving Beyond Access: College Success for Low-Income. First-Generation Students, Washington, DC: Pell Institute for the Study of Opportunity in Higher Education 2008.

(34) Organic Chemistry II was taught in a traditional, accelerated summer format throughout the study. Organic Chemistry III was only offered during the regular academic terms.

(35) Regular terms are 10 weeks, while summer terms are 5 weeks.

(36) R Core Team. R: A Language and Environment for Statistical Computing; R Foundation for Statistical Computing: Vienna, Austria, 2019.

(37) Wickham, H. Tidyverse: Easily Install and Load the "Tidyverse"; 2017.

(38) Quinn, M., McNamara, A. de la Rubia, E. A., Zhu. H, Ellis, S. Skimr: Compact and Flexible Summaries of Data; 2019.

(39) David Robinson, A. H. Broom: Convert Statistical Analysis Objects into Tidy Tibbles; 2019.

(40) Bryer, J. Likert: Analysis and Visualization Likert Items; 2019.

(41) Garnier, S. Viridis: Default Color Maps from "Matplotlib"; 2018.

(42) Zusho, A.; Pintrich, P. R.; Coppola, B. Skill and Will: The Role of Motivation and Cognition in the Learning of College Chemistry. Int. J. Sci. Educ. 2003, 25 (9), 1081-1094.

(43) Glaser, B.; Strauss, A. The Discovery of Grounded Theory. London: Weidenfeld and Nicholson 1967, 24 (25), 288-304.

(44) Bellert, A. Effective Re-Teaching. Australian Journal of Learning Difficulties 2015, 20 (2), $163-183$.

(45) Marzano, R. J.; Pickering, D. J.; Pollock, J. E. Classroom Instruction That Works: Research-Based Strategies for Increasing Student Achievement; Association for Supervision and Curriculum Development, 2001.

(46) Marzano, R. J. Reviving Reteaching. Educ. Leadersh. 2010, 68 (2), 82-83. 